\title{
Extracts of Ascaris suum egg and adult worm share similar immunosuppressive properties
}

V.M.O. Souza,

E.L. Faquim-M auro and M.S. Macedo
Departamento de Imunologia, Instituto de Ciências Biomédicas, Universidade de São Paulo, São Paulo, SP, Brasil

\section{Correspondence}

M.S. Macedo

Departamento de Imunologia ICB/USP

Av. Prof. Lineu Prestes, 1730

05508-900 São Paulo, SP

Brasil

Fax: + 55-11-3818-7224

E-mail: mamacedo@usp.br

Research supported by FAPESP. V.M.O. Souza was the recipient of a fellowship from FAPESP

(No. 96/8101-3).

Received May 7, 2001

Accepted October 10, 2001

\section{Abstract}

Adult Ascaris suum body extract (Asc) prepared from male and female worms (with stored eggs) down-regulates the specific immune response of DBA/2 mice to ovalbumin (OA) and preferentially stimulates a Th2 response to its own components, which is responsible for the suppression of the OA-specific Th1 response. Here, we investigated the participation of soluble extracts prepared from male or female worms or from eggs (E-Asc) in these immunological events. Extracts from either sex (1 mg/animal) or E-Asc ( 0.35 or $1 \mathrm{mg}$ protein/ animal) suppressed the delayed-type hypersensitivity (DTH) reaction (60-85\%), proliferative response (50-70\%), IL-2 and IFN- $\gamma$ secretion (below detection threshold) and IgG1 antibody production (70-90\%) of DBA/ 2 mice to OA. A dose of $0.1 \mathrm{mg}$ E-Asc/animal did not change DTH or proliferation, but was as effective as $0.35 \mathrm{mg}$ in suppressing IL-2 and IFN- $\gamma$, and OA-specific IgG1 antibodies. Lymph node cells from DBA/2 mice injected with Asc (1 mg/animal) or a high dose of E-Asc (1 mg protein/animal) secreted IL-4 upon in vitro stimulation with concanavalin A. As previously demonstrated for Asc, the cytokine profile obtained with the E-Asc was dose dependent and changed towards $\mathrm{Th} 1$ when a low dose $(0.1 \mathrm{mg}$ protein/animal $)$ was used. Taken together, these results suggest that adult worms of either sex and eggs induce the same type of $\mathrm{T}$ cell response and share similar immunosuppressive properties.

\section{Introduction}

Helminth parasites induce a predominant Th2-type response in the host, which is associated with both protective immunity and chronic states of disease (1-3). It was observed in some infections that the development of Th2 cells is specific for certain stages of the parasite life cycle and can downregulate the Th1 response. In murine schistosomiasis only egg antigens stimulate IL-4, IL-5 and IL-10 secretion (4,5), while mice
Key words

- Ascaris suum

- Immunosuppression

- Adult worms

- Eggs

- Cytokines exposed to larvae or adult worms in unisexual infections produce mainly IL-2 and IFN- $\gamma$. Furthermore, after the onset of egg deposition the Th1 response to larval stage is inhibited (6) as also is the response to nonparasite antigens like sperm whale myoglobin (7) and HIV glycoprotein $(8,9)$. In contrast, adult worms and infective larval form (L3) from species of Brugia elicit a high production of IL- 4 , whereas IFN- $\gamma$ secretion is sustained throughout infection in response to microfilariae, with IL-4 being secreted 
later on $(10,11)$. A Th2 response to Brugia malayi, previously induced by continuous stimulation, alters the typical Th1 response to mycobacterial antigen purified protein derivative, inducing IL-4 and IL-5 production, besides IFN- $\gamma(12)$. In addition, in concurrent infections the expansion of the Th2 response changes the course of disease mediated by Th1 cytokines. For example, AKR mice become resistant to Trichuris muris when infected with Schistosoma mansoni (13) and attenuated L3 of B. pahangi downregulates the murine susceptibility to cerebral malaria induced by Plasmodium berghei in BALB/c mice (14).

We have demonstrated that adult Ascaris suum body extract, prepared from male and female worms (with stored eggs), impairs the humoral and cell-mediated immune responses to the unrelated antigen ovalbumin (OA). High doses of adult worm extract preferentially induce a Th2 response to its own antigens, with high levels of IL-4 and IL-10 (15). The extract was previously fractionated by gel filtration and three peaks, named PI, PII and PIII, were obtained. PI components were responsible for the suppression of the OA-specific response, whereas PIII components were not suppressive and stimulated anti-adult worm extract IgE antibodies (16,17). In vivo treatment with anti-IL-4 and anti-IL-10 monoclonal antibodies in OA plus adult worm extractimmunized mice abolishes the effects of adult A. suum body extract on the Th1-related parameters of the immune response to OA. These results indicate the important role of these cytokines in the down-regulation of this response (18).

Although the suppressive effects of adult A. suum body extract have been quite well established, it is not clear which of its components is responsible for this immunosuppression. Therefore, in the present study we worked with soluble extracts prepared from A. suum male or female worms or eggs obtained from female uteri (M-Asc, F-Asc and
E-Asc, respectively) and assessed their effects on the OA-specific response and the pattern of cytokines and antibody isotypes elicited by them. Our results indicate that adult worms and eggs possess similar immunosuppressive properties.

\section{Material and Methods}

\section{Animals}

Seven- to eight-week-old male DBA/2 mice were used for immunization. The animals were bred in the animal house facilities of the Department of Immunology, ICB/University of São Paulo, São Paulo, SP, Brazil.

\section{Antigens and antibodies}

OA (grade II and V) was obtained from Sigma (St. Louis, MO, USA). Adult worm $A$. suum extracts: live male and female worms were separated by sex and the extracts prepared as previously described (19). The extracts contained $50 \%$ protein. Egg extract: briefly, uteri obtained from female worms were homogenized in an Ultra-Turrax apparatus (Janke and Kunkel, Staufen, Germany). After centrifugation at $13,000 \mathrm{~g}$ for $1 \mathrm{~h}$, the pellet was frozen in liquid nitrogen and macerated in the presence of glass powder. This mixture was diluted in borate-buffered saline, $\mathrm{pH} 8.0$ (equal volumes), stirred overnight at $4^{\circ} \mathrm{C}$, and then centrifuged at 13,000 $g$ for $1.5 \mathrm{~h}$. The supernatant was filtered through a 22- $\mu \mathrm{m}$ membrane (Millipore Co., Bedford, MA, USA), dialyzed against distilled water, centrifuged again, aliquoted, and lyophilized. Biotinylated isotype-specific goat anti-mouse antibodies were purchased from Southern Biotechnology Associates, Inc. (Birmingham, AL, USA). Monoclonal antibodies and recombinant cytokine standards for cytokine assays were obtained from hybridomas or kindly provided by Dr. R.L. Coffman, DNAX Research Institute, Palo Alto, CA, USA. 


\section{Immunization}

Groups of 5-7 mice were injected subcutaneously ( $s c$ ) with $100 \mu \mathrm{g}$ OA plus $1 \mathrm{mg} \mathrm{F}$ Asc or M-Asc emulsified in complete Freund's adjuvant (CFA) (Sigma) on both sides of the base of the tail $(0.2 \mathrm{ml} /$ animal $)$. Another group received only OA in CFA. For E-Asc, $100 \mu \mathrm{g}$ OA plus $1,0.35$ or $0.1 \mathrm{mg}$ protein/animal emulsified in CFA were used. The experiments were repeated three times.

\section{Hypersensitivity reactions}

Hypersensitivity reactions were elicited 8 days after immunization by injection of 30 $\mu l$ of $2 \%$ aggregated $\mathrm{OA}\left(1 \mathrm{~h}, 70^{\circ} \mathrm{C}\right)$ into one of the hind footpads and the same volume of saline in the other. Nonimmunized mice were equally injected and used as test control for nonspecific swelling. Footpad swelling was monitored periodically from 3 to $24 \mathrm{~h}$ using a pocket thickness gauge (Mitutoyo Mfg. Co. Ltd., Tokyo, Japan) and is reported as the increase in thickness relative to the saline-injected paw. The results are reported as the arithmetic mean \pm SEM for each group. Two-way analysis of variance followed by the multiple comparisons Tukey test (20) was used to compare the differently immunized groups.

\section{Proliferation assay}

Nine days after immunization, cell suspensions from inguinal and periaortic lymph nodes (LN) of 5 mice were prepared in RPMI 1640 (Sigma) supplemented with $10 \mathrm{mM}$ HEPES, $50 \mu \mathrm{M}$ M2-mercaptoethanol, 216 mg L-glutamine/l, and 5\% FCS. Triplicate preparations of cells $\left(5 \times 10^{5} /\right.$ well $)$ were distributed into 96-well flat-bottomed microplates (Costar, Cambridge, MA, USA) and incubated with OA, F-Asc, M-Asc (100 $\mu \mathrm{g} / \mathrm{ml}$ each), E-Asc (50 $\mu \mathrm{g}$ protein $/ \mathrm{ml})$ or 2.5 $\mu \mathrm{g} / \mathrm{ml}$ concanavalin A (Con A; Sigma) in a humidified $\mathrm{CO}_{2}$ incubator for 62 or $96 \mathrm{~h}$.
Cell proliferation was measured by $\left[{ }^{3} \mathrm{H}\right]-$ thymidine incorporation $(2 \mathrm{Ci} / \mathrm{ml}$; DuPont, Boston, MA, USA). One $\mu \mathrm{Ci}$ /well was added $18 \mathrm{~h}$ before cell harvesting and incorporated $\left[{ }^{3} \mathrm{H}\right]$-thymidine was determined by liquid scintillation spectrometry. The SD of mean count/min incorporated by triplicate cultures was less than $10 \%$. The results are reported as stimulation index (mean count/min of $\left[{ }^{3} \mathrm{H}\right]$-thymidine incorporated by stimulated LN cells divided by mean count/min incorporated by unstimulated cells).

\section{Cytokine assays}

The cell suspensions prepared for the proliferation assay were added to 24-well tissue culture plates (Costar) at a final concentration of 10 or $6 \times 10^{6}$ cells $/ \mathrm{ml}$. The cells were stimulated with OA, F-Asc, M-Asc $(500 \mu \mathrm{g} / \mathrm{ml}$ each $)$, E-Asc $(250 \mu \mathrm{g}$ protein $/ \mathrm{ml})$ or Con A $(5 \mu \mathrm{g} / \mathrm{ml})$. Supernatants were harvested after $24 \mathrm{~h}$ (cultures of $10 \times 10^{6}$ cells) or $72 \mathrm{~h}$ (cultures of $6 \times 10^{6}$ cells) and assayed for cytokine content. All cytokines were measured by specific two-site sandwich ELISA using the following monoclonal antibodies: XMG 1.2 and biotinylated AN 18 for IFN- $\gamma$; JES6-IA12 and biotinylated JES65H4 for IL-2, and BVD-1D11 and biotinylated BVD6-24G2 for IL-4. Binding of the biotinylated antibodies was determined using the streptavidin-peroxidase conjugate (Sigma) and ABTS (2,2'-azinobis(3-ethylbenzthiazoline-6-sulfonic acid; Sigma) solution in $0.1 \mathrm{M}$ citrate buffer plus $\mathrm{H}_{2} \mathrm{O}_{2}$. The plates were read $(410 \mathrm{~nm})$ in an automated ELISA reader (Dynatech MR 5000). Samples were quantified by comparison with standard curves of purified recombinant cytokines.

\section{Detection of antibody isotypes}

Plasma obtained 9 days after immunization was tested for IgG1 and IgG2a antibodies using antigen-coated 96-well plates (20 
Figure 1. Hypersensitivity reactions in mice immunized with ovalbumin (OA), $O A+$ Ascaris suum female (F-AsC) or male (MAsc) extract (A), or egg (E-Asc) extract $(B)$ at different protein doses (1, 0.35 and $0.1 \mathrm{mg}$ ). The mice were challenged 8 days later with aggregated $O A$ in the footpad. Nonimmunized mice (N) were also challenged in the same way for nonspecific swelling. The results represent the mean \pm SEM for 5-7 animals/ group. $* \mathrm{P}<0.05$ compared with the OA-immunized group (Tukey test). $\mu \mathrm{g} / \mathrm{ml} \mathrm{OA}, 10 \mu \mathrm{g} / \mathrm{ml} \mathrm{F-Asc} \mathrm{or} \mathrm{M-Asc,} \mathrm{and} 1$ $\mu \mathrm{g} / \mathrm{ml} \mathrm{E-Asc)}$ and biotinylated goat antimouse monospecific antisera. The reactions were developed with the streptavidin-peroxidase conjugate (Sigma), o-phenylenediamine and $\mathrm{H}_{2} \mathrm{O}_{2}$. The results are reported as the mean absorbance of samples/group ( \pm SEM) at various plasma dilutions. Analysis of variance followed by the multiple comparisons Tukey test was employed to com-
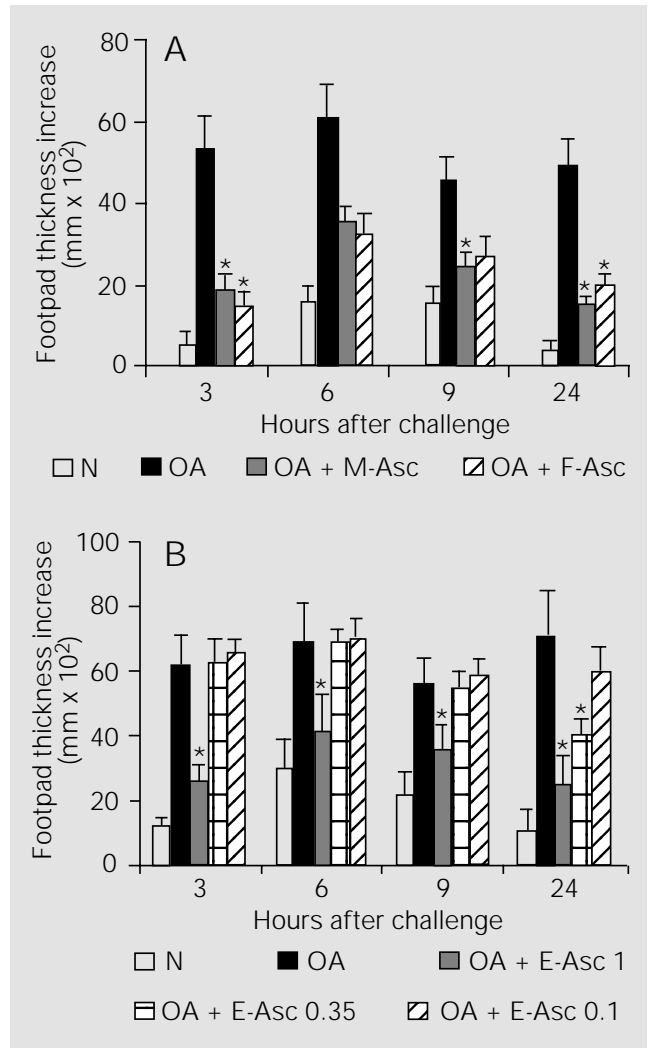

Table 1. Proliferative response of lymph node cells from mice immunized with ovalbu$\min (\mathrm{OA})$ or OA plus female or male adult worm extract.

\begin{tabular}{llrrr}
\hline Cells & OA & F-Asc & M-Asc & Con A \\
\hline OA & $7.9^{*}$ & 1.9 & 2.5 & 3.3 \\
OA + F-Asc & 1.0 & 13.2 & 14.4 & 5.2 \\
OA + M-Asc & 1.1 & 10.3 & 11.8 & 3.6
\end{tabular}

Inguinal and periaortic lymph node cells from mice immunized 9 days before with $O A$, $\mathrm{OA}+\mathrm{F}$-Asc or M-Asc in complete Freund's adjuvant were stimulated with $100 \mu \mathrm{g} / \mathrm{ml}$ $\mathrm{OA}, 100 \mu \mathrm{g} / \mathrm{ml} \mathrm{F-Asc}$ or M-Asc, or $2.5 \mu \mathrm{g} / \mathrm{ml}$ Con A for $96 \mathrm{~h}$. F-Asc, M-Asc = female and male worm extract, respectively; Con $A=$ concanavalin $A$.

*Stimulation index calculated as described in Material and Methods. pare the antibody response among groups (20).

\section{Results}

\section{Effect of worm and egg extracts on OA-specific hypersensitivity reactions}

The development of hypersensitivity reactions in mice immunized with OA alone, OA plus adult worm extracts or different doses of E-Asc after challenge with aggregated $\mathrm{OA}$ in the footpad were compared on day 8. As shown in Figure 1A, the immediate $(3 \mathrm{~h})$ and delayed-type hypersensitivity (DTH) $(24 \mathrm{~h})$ reactions to OA were reduced in animals that received OA + F-Asc or MAsc compared with OA-immunized mice. Regarding E-Asc (Figure 1B), the group immunized with OA $+1 \mathrm{mg}$ E-Asc showed a reduced immediate reaction and a DTH response that did not differ significantly from that of the nonimmunized group. Mice immunized with $\mathrm{OA}+0.35 \mathrm{mg}$ E-Asc showed only a reduced DTH reaction to OA. The hypersensitivity reactions of mice immunized with $\mathrm{OA}+0.1 \mathrm{mg}$ E-Asc were similar to those obtained in mice injected with $\mathrm{OA}$ alone.

\section{Effect of worm and egg extracts on lymphoproliferative response to $\mathrm{OA}$}

The proliferation of LN cells from mice immunized with OA and the different $A$. suum extracts was then measured after in vitro stimulation with the antigen or mitogen. The results presented in Table 1 show that simultaneous immunization with $\mathrm{OA}+$ F-Asc or M-Asc prevented LN cells from responding to $\mathrm{OA}$ in vitro when compared with the response of cells from mice immunized with $\mathrm{OA}$ alone. The proliferation of cells from the former groups when stimulated with Con A for $96 \mathrm{~h}$ was low. The same suppressive effect was caused by E-Asc, irrespective of the protein concentration of 
the extract used for immunization (Table 2). In this experiment, the cells were stimulated for $62 \mathrm{~h}$ and, therefore, the proliferation of OA-primed cells was lower in response to $\mathrm{OA}$ and higher in response to Con A. Consequently, a dose-dependent suppression could also be observed after Con A stimulation. The stimulation index of $\mathrm{LN}$ cells from mice immunized with $\mathrm{OA}+\mathrm{F}$-Asc or OA $+\mathrm{M}$ Asc was similar when cell cultures were restimulated in vitro with either F-Asc or MAsc. In comparison, the nonspecific proliferation of cells from OA-immunized mice when in vitro restimulated with these extracts was negligible (Table 1). The same was true for E-Asc that stimulated just the proliferation of OA + E-Asc-primed cells (Table 2).

\section{Effect of worm and egg extracts on cytokine and antibody production in response to $\mathrm{OA}$}

LN cells from the above groups were also cultured with OA or Con A for 24 or $72 \mathrm{~h}$ and the supernatants collected for quantification of secreted cytokines. Cytokine assays for adult worm-injected groups and for egg-in- jected groups were not performed at the same time. Cultures from mice immunized with OA + F-Asc, M-Asc or different doses of E-Asc did not have any detectable IL-2 or IFN- $\gamma$ when restimulated in vitro with OA compared to those from OA-immunized mice (Table 3). The levels of these cytokines were also reduced upon stimulation with Con A, but the lowest dose $(0.1 \mathrm{mg})$ of E-Asc was less suppressive. Regarding IL-4, high levels of this cytokine were only detected in cul-

Table 2. Proliferative response of lymph node cells from mice immunized with ovalbumin (OA) or OA plus Ascaris suum egg extract.

\begin{tabular}{llrr}
\hline Cells & OA & E-Asc & Con A \\
\hline OA & $3.0^{*}$ & 0.0 & 37.0 \\
OA + E-Asc $(0.1 \mathrm{mg})$ & 1.9 & 13.0 & 30.0 \\
OA + E-Asc $(0.35 \mathrm{mg})$ & 1.5 & 11.0 & 21.0 \\
OA + E-Asc (1 mg) & 1.6 & 11.0 & 19.0
\end{tabular}

Inguinal and periaortic lymph node cells from mice immunized 9 days before with OA or OA + E-Asc at different protein doses were stimulated with $100 \mu \mathrm{g} / \mathrm{ml} \mathrm{OA}, 50 \mu \mathrm{g}$ protein/ml E-Asc or $2.5 \mu \mathrm{g} /$ $\mathrm{ml}$ Con $\mathrm{A}$ for $62 \mathrm{~h}$. E-Asc $=$ Ascaris suum egg extract; Con $\mathrm{A}=$ concanavalin $\mathrm{A}$.

*Stimulation index calculated as described in Material and Methods.

Table 3. Synthesis of IL-2, IFN- $\gamma$ and IL-4 by lymph node cells from mice immunized with ovalbumin (OA) or OA plus female, male or egg extract.

\begin{tabular}{|c|c|c|c|c|c|c|}
\hline \multirow[t]{2}{*}{ Cells } & \multicolumn{2}{|c|}{ IL-2 (ng/ml) } & \multicolumn{2}{|c|}{ IFN- $\gamma(\mathrm{ng} / \mathrm{ml})$} & \multicolumn{2}{|c|}{ IL-4 (pg/ml) } \\
\hline & OA & Con A & OA & Con A & OA & Con A \\
\hline \multicolumn{7}{|l|}{ A. } \\
\hline OA & $0.7 \pm 0.1$ & $46.2 \pm 2.7$ & $25.7 \pm 0.8$ & $44.4 \pm 2.3$ & $<78.0$ & $<78.0$ \\
\hline $\mathrm{OA}+\mathrm{F}-\mathrm{Asc}$ & $<0.19$ & $15.3 \pm 1.4$ & $<1.56$ & $27.3 \pm 2.8$ & $<78.0$ & $597.0 \pm 74.0$ \\
\hline $\mathrm{OA}+\mathrm{M}-\mathrm{AsC}$ & $<0.19$ & $18.6 \pm 1.1$ & $<1.56$ & $16.8 \pm 0.4$ & $<78.0$ & $433.0 \pm 28.0$ \\
\hline \multicolumn{7}{|l|}{ B. } \\
\hline OA & $0.8 \pm 0.1$ & $23.8 \pm 0.3$ & $8.8 \pm 1.4$ & $37.1 \pm 0.3$ & $<31.2$ & $<31.2$ \\
\hline $\mathrm{OA}+\mathrm{E}-\mathrm{Asc}(1 \mathrm{mg})$ & $<0.19$ & $5.4 \pm 0.5$ & $<1.56$ & $9.4 \pm 0.6$ & $<31.2$ & $80.7 \pm 14.0$ \\
\hline $\mathrm{OA}+\mathrm{E}-\mathrm{Asc}(0.35 \mathrm{mg})$ & $<0.19$ & $6.8 \pm 0.1$ & $<1.56$ & $10.3 \pm 0.8$ & $<31.2$ & $<31.2$ \\
\hline $\mathrm{OA}+\mathrm{E}-\mathrm{Asc}(0.1 \mathrm{mg})$ & $<0.19$ & $14.2 \pm 0.2$ & $<1.56$ & $19.8 \pm 0.5$ & $<31.2$ & $<31.2$ \\
\hline
\end{tabular}

Inguinal and periaortic lymph node cells from mice immunized 9 days before with OA, OA + F-Asc, M-Asc or E-Asc in complete Freund's adjuvant were stimulated with $500 \mu \mathrm{g} / \mathrm{ml} \mathrm{OA}$ or $5 \mu \mathrm{g} / \mathrm{ml}$ Con A. IL-2 was quantified in supernatants harvested after $24 \mathrm{~h}$ and IFN $-\gamma$ and IL-4 in supernatants obtained after $72 \mathrm{~h}$. The results represent the mean \pm SD of duplicate cultures. Non-stimulated cells produced $<0.19 \mathrm{ng} / \mathrm{ml}$ of IL-2, $<1.56 \mathrm{ng} / \mathrm{ml}$ of IFN- $\gamma$ and $<31.2$ or $78.0 \mathrm{pg} / \mathrm{ml}$ of IL-4. For abbreviations, see legends to Tables 1 and 2 . 
Figure 2. Ovalbumin (OA)-specific IgG1 (A) and IgG2a (B) antibodies produced by OA or OA + Ascaris suum female (F-Asc)- or male (M-Asc) extract-immunized mice. Isotype levels were titrated by ELISA in normal (N) or immune plasma obtained after 9 days of immunization using monospecific antisera. The results represent the mean \pm SEM absorbance for 5-7 animals. $* \mathrm{P}<0.01$ compared with the OAimmunized group (Tukey test).

Figure 3. Ovalbumin (OA)-specific IgG1 (A) and IgG2a (B) antibodies produced by OA or OA + Ascaris suum egg (E-Asc) extract-immunized mice $(1,0.35$ and $0.1 \mathrm{mg}$ ). Isotype levels were titrated by ELISA in normal $(\mathrm{N})$ or immune plasma obtained after 9 days of immunization using monospecific antisera. The results represent the mean \pm SEM absorbance for 5-7 animals. $* \mathrm{P}<0.05$ compared with the OAimmunized group. $+P<0.05$ compared with the OA + E-Asc (1 $\mathrm{mg}$ )-immunized group (Tukey test). tures from OA + F-Asc- or M-Asc-immunized mice stimulated with Con A (Table 3A). IL-4 was also detected in the supernatant of LN cells from mice immunized with
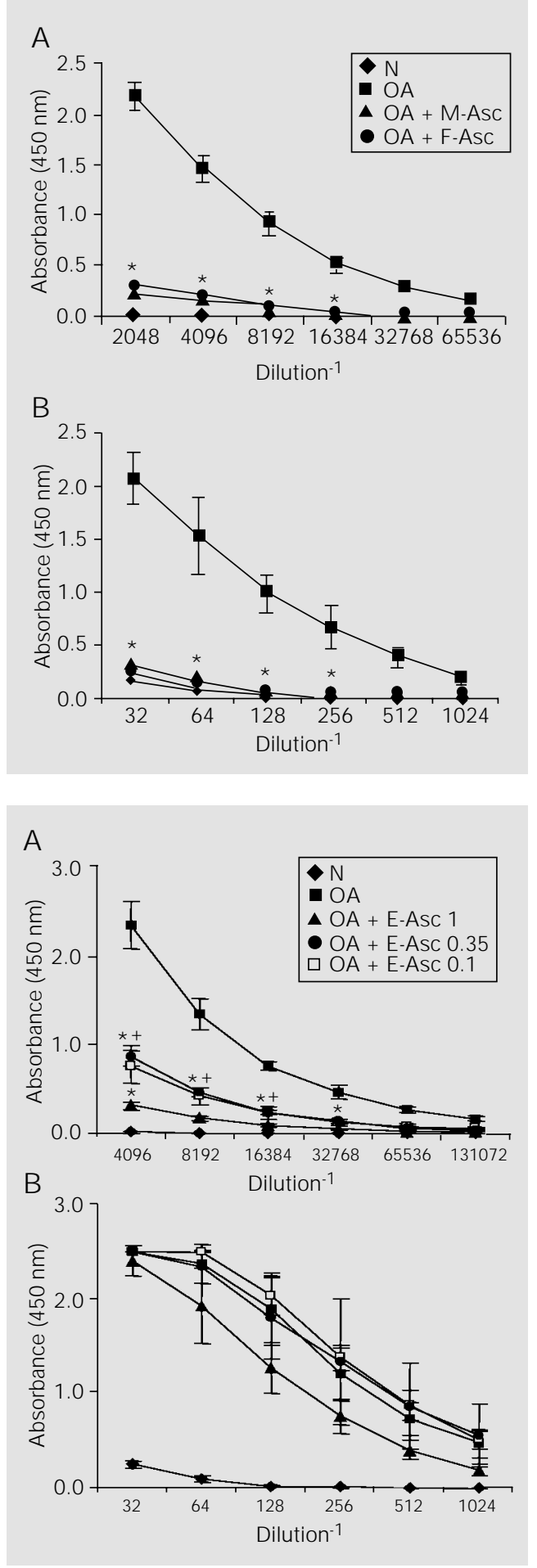

the highest dose (1 mg) of E-Asc after Con A stimulation (Table 3B).

Antibody levels were also assessed in plasma obtained from all groups on day 9 . IgG1 and IgG2a antibody production was strongly inhibited in mice immunized with OA plus adult worm extracts (Figure 2). The egg extract also had a suppressive effect on anti-OA IgG1 antibody production, with the highest dose being more effective (Figure $3 \mathrm{~A})$. IgG2a levels were not significantly different among the immunized groups, although the group injected with $1 \mathrm{mg}$ of E-Asc repeatedly responded less than the other two (Figure 3B).

\section{Profile of cytokines and antibody isotypes in response to adult worm and egg extracts}

Cytokines were also measured in supernatants of LN cell cultures from mice injected with the different adult worm extract preparations after in vitro restimulation with the respective extract. Table 4 shows that F-Asc induced more IFN- $\gamma$ and IL-4 than M-Asc. In addition, more IL-2 and IFN- $\gamma$, and less IL-4 were produced as the immunizing dose of E-Asc was reduced.

To analyze the isotypes elicited by each extract the ELISA plates were coated with the respective antigens. F-Asc and M-Asc induced the same amounts of antigen-specific IgG1 and IgG2a antibodies (Figure 4). A dose-dependent production of IgG1 antibodies was observed in mice immunized with E-Asc (Figure 5A). IgG2a antibodies were mostly induced by the highest doses of E-Asc (Figure 5B).

\section{Discussion}

Unisexual infections have been an important experimental model to study the type of immune response induced by helminths $(5,10)$. In the present study, immunization with extracts of $A$. suum prepared from adult worms of either sex or from eggs allowed us 
to show that male and female body components and egg contents elicit the same type of $\mathrm{T}$ cell response and possess similar suppressive properties on the immune response to an unrelated antigen.

The male and female extracts exerted an identical suppressive effect on OA-specific immediate and DTH reactions, proliferative response, IL- 2 and IFN- $\gamma$ secretion, and IgG1 and $\mathrm{IgG} 2 \mathrm{a}$ antibody production. Extracts of females prepared from worms without a uterus had the same effect, indicating the presence of suppressive components in the female body in the absence of eggs (21).

Mice injected with the egg extract displayed a dose-dependent inhibition of hypersensitivity reactions and $\operatorname{IgG} 1$ antibody response to $\mathrm{OA}$ and of $\mathrm{LN}$ cell proliferation and of cytokine secretion after in vitro stimulation with Con A. In addition, the LN cells from the groups of mice injected with different doses of E-Asc did not secrete detectable IL-2 or IFN- $\gamma$ after in vitro restimulation with OA compared to the group immunized with OA alone, indicating a dramatic effect on these Th1-type cytokines. When these LN cells were restimulated with E-Asc, the profile of cytokines detected in cell cultures was similar to that obtained after immunization with $A$. suum extract prepared from adult worms (15). The highest dose of EAsc, which was more suppressive, induced more IL-4 and less IL- 2 and IFN- $\gamma$, whereas the opposite was true for the lowest dose that was less suppressive.

These results indicate that the suppressive mechanisms induced by egg contents seem to be similar to those induced by adult worm components, being mediated by the same cytokines (18). However, E-Asc seems to contain less suppressive components than F-Asc or M-Asc, since the latter had a more drastic effect when $500 \mu \mathrm{g}$ of protein was used compared with $1 \mathrm{mg}$ of the former.

In $S$. mansoni infection, the Th1 response present during the larval stage is inhibited by the Th2 response induced after egg deposi- tion (6). The Th2 response to egg antigens, however, develops through an early and transient Th0 stage during which IL-2, IFN- $\gamma$, IL4 , IL-5 and IL-10 are produced $(22,23)$. Fractionation of egg antigens revealed also the presence of IFN- $\gamma$ inducers among the protein fractions (24).

It is interesting to note that a monoclonal antibody prepared against a high molecular weight suppressive component from adult worm body extract was able to react with

Table 4. Cytokine profile in response to adult worm or egg extract.

\begin{tabular}{lrrr}
\hline Cells & IL-2 $(\mathrm{ng} / \mathrm{ml})$ & IFN- $\gamma(\mathrm{ng} / \mathrm{ml})$ & \multicolumn{1}{c}{ IL-4 $(\mathrm{pg} / \mathrm{ml})$} \\
\hline OA + F-Asc & $1.8 \pm 0.2$ & $13.4 \pm 0.8$ & $170.0 \pm 10.0$ \\
OA + M-Asc & $2.4 \pm 0.3$ & $6.4 \pm 0.2$ & $96.0 \pm 7.0$ \\
OA + E-Asc (1 mg) & $1.8 \pm 0.1$ & $4.2 \pm 0.5$ & $104.8 \pm 6.7$ \\
OA + E-Asc (0.35 mg) & $2.1 \pm 0.1$ & $7.8 \pm 0.2$ & $83.0 \pm 6.9$ \\
OA + E-Asc (0.1 mg) & $4.5 \pm 0.1$ & $14.9 \pm 0.7$ & $55.7 \pm 6.5$
\end{tabular}

Inguinal and periaortic lymph node cells from mice immunized 9 days before with $O A$ + F-Asc, M-Asc or E-Asc in complete Freund's adjuvant were stimulated with $500 \mu \mathrm{g} /$ $\mathrm{ml}$ F-Asc or M-Asc or $250 \mu \mathrm{g}$ protein/ml E-Asc. IL-2 was quantified in supernatants harvested after $24 \mathrm{~h}$ and IFN- $\gamma$ and IL-4 in supernatants obtained after $72 \mathrm{~h}$. The results represent the mean \pm SD of duplicate cultures. Non-stimulated cells produced $<0.19$ $\mathrm{ng} / \mathrm{ml}$ of IL-2, $<1.56 \mathrm{ng} / \mathrm{ml}$ of IFN- $\gamma$ and $<31.2 \mathrm{pg} / \mathrm{ml}$ of IL-4. For abbreviations, see legends to Tables 1 and 2 .

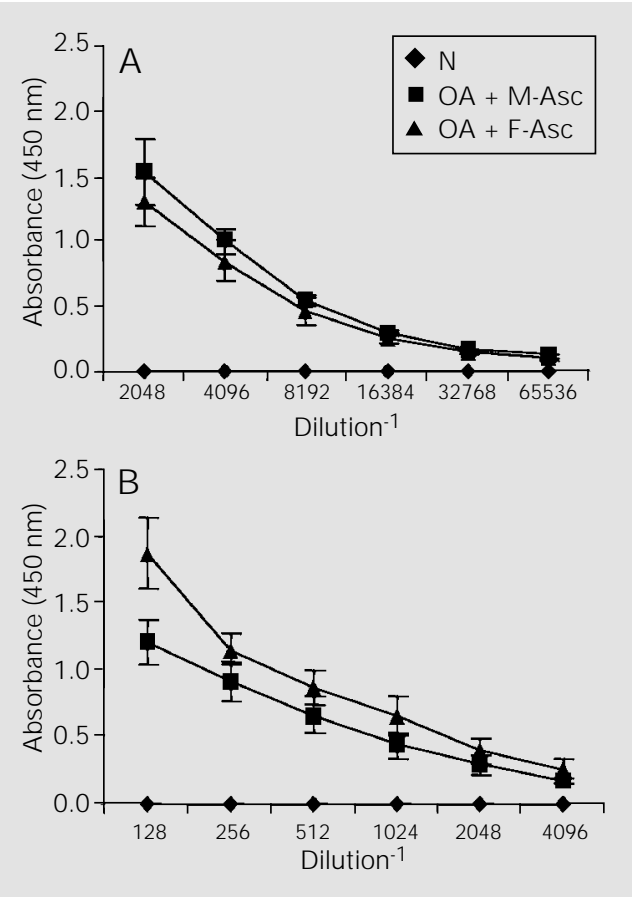

Figure 4. Female or male Ascaris suum (Asc)-specific IgG1 (A) and IgG2a (B) antibodies produced by mice immunized with ovalbumin $(\mathrm{OA})+$ female $(\mathrm{F}$ Asc) or male (M-Asc) extract. Isotype levels in normal $(\mathrm{N})$ or immune plasma were titrated by ELISA using monospecific antisera. The results represent the mean \pm SEM absorbance for 5-7 animals. 
embryonated eggs, L1, L2 and L3/4 larvae, indicating that the suppressive protein was present in different stages of $A$. suum lifecycle (Enobe CS, Oshiro TM and MacedoSoares MF, unpublished data). Therefore, this component could be responsible for the immunosuppression obtained with the male, female and egg extract. Indeed, the presence of similar high molecular weight components in E-Asc was confirmed when this extract was fractionated on a Sephacryl S300 chromatography column and the suppressive effect of the first peak was demon-

Figure 5. Ascaris suum egg (EAsc)-specific lgG1 (A) and IgG2a (B) antibodies produced by mice immunized with different doses of E-Asc (1, 0.35 and $0.1 \mathrm{mg}$ ). Isotype levels in normal $(\mathrm{N})$ or immune plasma were titrated by ELISA using monospecific antisera. The results represent the mean \pm SEM absorbance for 5-7 animals. $* P<0.05$ compared with OA + E-Asc (1 mg)-immunized group (Tukey test). $+\mathrm{P}<0.05$ compared with $\mathrm{OA}+$ E-Asc (0.35 mg)-immunized group (Tukey test).

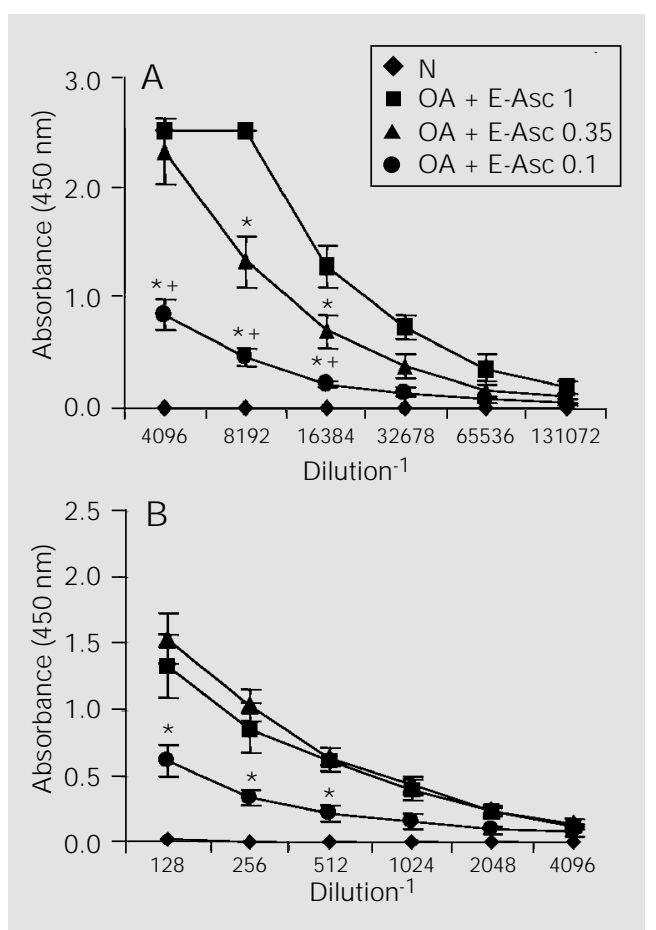

strated on the $\operatorname{IgE}$ antibody response to $\mathrm{OA}$ (21). Using the same experimental protocol, additional suppressive components were also identified in the third peak which contains low molecular mass proteins $(29 \mathrm{kDa})$, in contrast to the results obtained with PIII isolated from the adult body extract $(16,17)$. The presence of egg-specific antigens, not found in adult worms, had been already reported in A. suum by Justus and Ivey (25). We also noticed by SDS-PAGE that proteins with molecular masses between 27.2 and 19 $\mathrm{kDa}$ were present only in E-Asc (21).

The different antigenic profiles of E-Asc might also explain why the production of egg-specific IgG2a antibodies and the levels of IFN- $\gamma$ obtained in response to different doses of this extract were not correlated. It is well known that IFN- $\gamma$ can enhance antigenspecific as well as polyclonal IgG2a responses, but is not required for the induction of this isotype in all murine antibody responses (26). B cells can also switch to IgG2a producers when stimulated by Th2 clones, although much less (about 20-fold) than when activated by Th1 clones (27). Thus, some egg-specific antigens could be stimulating an $\mathrm{IgG} 2 \mathrm{a}$ antibody response in a dose-dependent, but IFN- $\gamma$-independent, way.

In conclusion, A. suum egg content shares immunosuppressive properties with adult worm components, but also contains other constituents with biological activities that deserve further characterization.

\section{References}

1. Pearce EJ \& Reiner SL (1995). Induction of Th2 responses in infectious diseases. Current Opinion in Immunology, 7: 497504.

2. J ankovic $D \&$ Sher $A$ (1996). Initiation and regulation of $C D 4+T$-cell function in host parasite models. Chemical Immunology, 63: 51-65.

3. Else KJ \& Finkelman FD (1998). Intestinal nematode parasites, cytokine and effec- tor mechanisms. International J ournal for Parasitology, 28: 1145-1158.

4. Sher A, Fiorentino D, Caspar P, Pearce E \& Mosmann TR (1991). Production of IL10 by CD4+ $\mathrm{T}$ lymphocytes correlates with down-regulation of Thl cytokine synthesis by helminth infection. J ournal of Immunology, 147: 2713-2716.

5. Grzych J M, Pearce E, Cheever A, Caulada ZA, Caspar P, Hieny S \& Sher A (1991).
Egg deposition is the major stimulus for the production of Th2 cytokines in murine schistosomiasis mansoni. J ournal of Immunology, 146: 1322-1327.

6. Pearce EJ , Caspar P, Grzych J M, Lewis FA \& Sher A (1991). Downregulation of the Th1 cytokine production accompanies induction of Th2 response by a parasitic helminth, Schistosoma mansoni. J ournal of Experimental Medicine, 173: 159-166. 
7. Kullberg MC, Pearce EJ , Hieny SE, Sher A \& Berzofsky JA (1992). Infection with Schistosoma mansoni alters Th1/Th2 cytokine response to a non-parasite antigen. J ournal of Immunology, 148: 32643270.

8. Actor J K, Shirai M, Kullberg MC, Buller RML, Sher A \& Berzofsky J A (1993). Helminth infection results in decreased virusspecific $\mathrm{CD}^{+}{ }^{+}$cytotoxic T-cell and Th1 cytokine responses as well as delayed virus clearance. Proceedings of the National Academy of Sciences, USA, 90: 948-952.

9. Actor J K, Marshall MA, Eltoum IA, Buller RML, Berzofsky J A \& Sher A (1994). Increased susceptibility of mice infected with Schistosoma mansoni to recombinant vaccinia virus: association of viral persistence with egg granuloma formation. European J ournal of Immunology, 24: 3050-3056.

10. Lawrence RA, Allen JE, Osborne J \& Maizels RM (1994). Adult and microfilarial stages of the filarial parasite Brugia malayi stimulate contrasting cytokine and Ig isotype response in BALB/C mice. J ournal of Immunology, 153: 1216-1224.

11. Osbome J , Hunter SJ \& Devaney E (1996). Anti-interleukin-4 modulation of the Th2 polarized response to the parasitic nematode Brugia pahangi. Infection and Immunity, 64: 3461-3466.

12. Pearlman E, Kazura J, Hazlett J r FE \& Boom WH (1993). Modulation of murine cytokine responses to mycobacterial antigens by helminth-induced T helper 2 cell response. J ournal of Immunology, 151: 4857-4864.

13. Curry AJ, Else KJ , J ones F, Bancroft A, Grencis RK \& Dunne DW (1995). Evidence that cytokine-mediated immune interaction induced by Schistosoma mansoni alters disease outcome in mice concurrently infected with Trichuris muris. J ournal of Experimental Medicine, 181: 769774.

14. Yan $Y$, Inuo $G$, Akao N, Tsukidate $S \&$ Fujita K (1997). Down-regulation of murine susceptibility to cerebral malaria by inoculation with third-stage larvae of the filarial nematode Brugia pahangi. Parasitology, 114: 333-338.

15. Ferreira AP, Faquim ES, Abrahamsohn IA $\&$ Macedo MS (1995). Immunization with Ascaris suum extract impairs T cell functions in mice. Cellular Immunology, 162: 202-209.

16. Soares MFM, Mota I\& Macedo MS (1992). Isolation of Ascaris suum components which suppress IgE antibody response. International Archives of Allergy and Immunology, 97: 37-43.

17. Faquim-Mauro EL \& Macedo MS (1998). The immunosuppressive activity of Ascaris suum is due to high molecular weight components. Clinical and Experimental Immunology, 114: 245-251.

18. Macedo MS, Faquim-Mauro E, Ferreira AP \& Abrahamsohn IA (1998). Immunomodulation induced by Ascaris suum extracts in mice: Effect of anti-interleukin-4 and anti-interleukin-10 antibodies. Scandinavian J ournal of Immunology, 47: 10-18.

19. Macedo MS \& Mota I (1980). Antigenic competition in IgE antibody production. I. Establishment of parameters involved in primary and secondary responses. Immunology, 40: 701-708.

20. Zar JH (1984). Biostatistical Analysis. Prentice-Hall, New J ersey, NY, USA.
21. Souza VMO (1999). Immunoregulatory properties of soluble extracts from Ascaris suum worms or eggs. Master's thesis, Instituto de Ciências Biomédicas, Universidade de São Paulo, São Paulo, SP, Brazil.

22. Vella AT \& Pearce EJ (1992). CD4 ${ }^{+}$response induced by Schistosoma mansoni eggs develops rapidly, through an early, transient, Th0-like stage. J ournal of Immunology, 148: 2283-2290.

23. Wynn TA, Eltoum I, Cheever AW, Lewis FA, Gause WC \& Sher A (1993). Analysis of cytokine mRNA expression during primary granuloma formation induced by eggs of Schistosoma mansoni. J ournal of Immunology, 151: 1430-1440.

24. Lukacs NW \& Boros DL (1992). Utilization of fractionated soluble egg antigens reveals selectively modulated granulomatous and lymphokine responses during murine schistosomiasis mansoni. Infection and Immunity, 60: 3209-3216.

25. J ustus DV \& Ivey MH (1969). Ascaris suum: Immunoelectrophoretic analysis of antigens in development stages. Experimental Parasitology, 26: 290-298.

26. Finkelman FD, Holmes J, Katona IMK, Urban J rJ F, Beckman MP, Park LS, Shooley $K A$, Coffman RL, Mosmann TR \& Paul WE (1990). Lymphokine control of in vivo immunoglobulin isotype selection. Annual Review of Immunology, 8: 303-333.

27. Mosmann TR \& Coffman RL (1989). TH1 and TH2 cells: different patterns of lymphokine secretion lead to different functional properties. Annual Review of Immunology, 7: 145-173. 